\title{
IDENTIFIKASI HIDROKUINON DALAM SABUN PEMUTIH PEMBERSIH WAJAH DI TIGA KLINIK KECANTIKAN DENGAN METODE KROMATOGRAFI LAPIS TIPIS DAN SPEKTROFOTOMETRI UV-VIS
}

\section{IDENTIFICATION OF HYDROCUINONES IN CLEANING BLEACHING SOAP FACE AT THREE BEAUTY CLINICS WITH THIN LAYER CHROMATOGRAPHY AND UV-VIS SPECTROPHOTOMETRY}

\author{
Risna Agustin, Destiana Eka Oktaviantari, Niken Feladita*
}

Prodi DIII Analis Farmasi dan Makanan Universitas Malahayati

Email : nkn.1202@gmail.com

\begin{abstract}
Liquid soap was a liquid skin shampoo made from soap material with the addition of the desired ingredients. Excess added hydroquinones in liquid soaps such as facial cleansing soap can cause hyperpigmentation of the skin. The use of hydroquinone according to BPOM regulations was a class of hard drugs that can only be used on the basis of a doctor's prescription. The purpose of this study was to find out whether there is hydroquinone on facial cleanser sold at three beauty clinics in Bandar Lampung. The sampling technique was done by purposive sampling. Samples were tested qualitatively by thin layer chromatography and UV-Vis spectrophotometry. Thin Layer Chromatography Principle is the separation of multi component compounds by using two phases of the stationary phase and the mobile phase. The stationary phase used is Silica Gel GF $254 \mathrm{~nm}$ and the mobile phase used is toluene and glacial acetic acid (8: 2). The result of $R f$ value difference is positive if $\leq 0,05$ and stated negative if result value $R f>0,05$. The results obtained from the three samples are all three contain negative hydroquinone due to the difference value $R f>0.05$ with the result $R f$ raw 0, 07 and $R f$ difference of each sample $A=0.185 B=0.185 C=0$, Then proceed with Spectrofotometric UV-Vis by comparing the spectrum of standard solution with the sample, obtained negative results on the three samples because the spectrum image of the standard solution and the sample is not identical.
\end{abstract}

Keywords : Face Cleansing Facial Soap, Hydroquinone, Beauty Clinic, Thin Layer Chromatography (TLC), UV-Vis Spectrophotometry.

\section{ABSTRAK}

Sabun cair merupakan sediaan pembersih kulit berbentuk cair yang terbuat dari bahan sabun dengan penambahan bahan-bahan yang diinginkan. Hidrokuinon yang ditambahkan secara berlebih dalam sabun cair seperti sabun pemutih pembersih wajah dapat menyebabkan hiperpigmentasi pada kulit. Penggunaan hidrokuinon menurut peraturan BPOM termasuk golongan obat keras yang hanya dapat digunakan berdasarkan resep dokter. Tujuan penelitian ini untuk mengetahui apakah terdapat hidrokuinon pada sabun pemuth pembersih wajah yang dijual pada tiga klinik kecantikan di Bandar Lampung. Teknik pengambilan sampel dilakukan secara purposive sampling. Sampel diuji secara kualitatif dengan metode kromatografi lapis tipis dan spektrofotometri UV-Vis. Prinsip Kromatografi Lapis Tipis yaitu pemisahan senyawa multi komponen dengan menggunakan dua fase yaitu fase diam dan fase gerak. Fase diam yang digunakan yaitu silika gel GF $254 \mathrm{~nm}$ dan fase gerak yang digunakan yaitu toluen dan asam asetat glasial (8:2). Hasil nilai selisih Rf dinyatakan positif jika $\leq 0,05$ dan dinyatakan negatif jika hasil nilai $\mathrm{Rf}>0,05$. Diperoleh hasil dari ketiga sampel tersebut ketiganya negatif mengandung zat hidrokuinon dikarenakan nilai selisih $\mathrm{Rf} \geq 0,05$ dengan hasil $\mathrm{Rf}$ baku 0,07 dan selisih Rf masing-masing sampel $A=0,185 B=0,185 \quad C=0$, Kemudian dilanjutkan dengan metode

Spektrofotometri UV-Vis dengan membandingkan spektrum larutan baku dengan sampel, diperoleh hasil negatif pada ketiga sampel karena gambar spektrum larutan baku dan sampel tidak identik.

Kata Kunci : Sabun Pemuth Pembersih Wajah, Hidrokuinon, Klinik Kecantikan, Kromatografi Lapis Tipis (KLT), Spektrofotometri UV-Vis.

\section{PENDAHULUAN}

Kecantikan semakin berkembang dari masa ke masa, bukan lagi hanya menjadi sebuah keinginan, melainkan sudah menjadi sebuah kebutuhan yang akhirnya berdampak pada semakin meningkatnya industri kosmetik di dunia, termasuk juga di Indonesia 
[4]. Menurut Peraturan Menteri Kesehatan Republik Indonesia Nomor 117/MenKes/PER/VII/2010 tentang Notifikasi Kosmetika, kosmetik adalah bahan atau sediaan yang dimaksudkan untuk digunakan pada bagian luar tubuh manusia (epidermis, rambut, kuku, bibir, dan organ genital bagian luar) atau gigi dan mukosa mulut terutama untuk membersihkan, mewangikan, merubah penampilan dan atau memperbaiki bau badan atau melindungi atau memelihara tubuh pada kondisi baik[6]. Bentuk kosmetika yang sering digunakan oleh masyarakat yaitu kosmetika perawatan kulit. Kosmetika perawatan kulit salah satunya adalah sabun. Ada beberapa agen pemutih yang diperbolehkan ditambahkan dalam sabun seperti Glycolic Acid, Lactic Acid, dan Alpha Hydroxy Acid dan ada juga beberapa agen pemutih yang dilarang ditambahkan dalam sabun salah satunya yaitu hidrokuinon. Menurut PERKA BPOM Republik Indonesia Nomor 18 Tahun 2015 Tentang Persyaratan Teknis Bahan Kosmetika kadar hidrokuinon yang diperbolehkan adalah tidak lebih dari $0,02 \%$ dalam cat kuku [2]. Efek samping pemakaian hidrokuinon secara umum dapat menyebabkan dermatitis kontak dalam bentuk bercak warna putih pada wajah atau hiperpigmentsi. Pemakaian hidrokuinon dalam jangka panjang tanpa menghindari eksposure sinar matahari efek yang ditimbulkan pada wajah bisa sebaliknya yaitu akan timbul flek atau spot yang bertambah bahkan bisa muncul bintik kekuningan atau keadaan kulit menjadi lebih buruk dari semula. Maka dari itu, peneliti ingin menguji varian kosmetik lain yaitu sabun pemutih pembersih wajah dengan judul Identifikasi hidrokuinon dalam sabun pemutih pembersih wajah pada tiga klinik kecantikan di Bandar Lampung dengan metode Kromatografi Lapis Tipis dan Spektrofotometri UV-Vis. Dilakukan dengan metode Kromatografi Lapis tipis karena metode ini merupakan metode yang cepat, mudah dan dapat memisahkan senyawa multi komponen secara kualitatif dan kuantitatif sehingga dapat dideteksi

dengan detektor UV $254 \mathrm{~nm}$ dengan penampak bercak atau zat tersebut berfluoresensi di bawah sinar UV. Sedangkan Senyawa hidrokuinon merupakan senyawa polar yang memiliki gugus benzen serta terdapat kromofor dan ausokrom pada struktur

kimianya sehingga memenuhi syarat untuk di analisis menggunakan metode spektrofotometri 3].

\section{MEODE PENELITIAN}

Alat dan Bahan
Erlenmeyer, Gelas kimia, Chamber, Plat KLT, Spektrofotometri UV-Vis

Pipet ukur, Pipa kapiler, Beaker glass, Labu Ukur 10 $\mathrm{ml}$, Kuvet, Neraca analitik, Lampu UV254, Labu ukur $25 \mathrm{ml}, \mathrm{HCL} 4 \mathrm{~N}$, Fase gerak \{Toluen : Asam asetat glasial ( 8:2), Aquadest, Etanol $96 \%$, Natrium Sulfat, Hidrokuinon, Sampel Sabun Pembersih Wajah.

\section{Prosedur Kerja Penelitian \\ Prosedur Kerja Kromatografi Lapis Tipis \\ Pembuatan Larutan Uji}

Timbang seksama $1.5 \mathrm{~g}$ sampel dalam beaker glass $25 \mathrm{ml}$. Tambahkan $15 \mathrm{ml}$ etanol $96 \%$ sedikit demi sedikit, kemudian campur. Homogenkan ke dalam tangas ultrasonik selama 10 menit dan didinginkan hingga suhu ruang. Tuang ke dalam labu ukur $25 \mathrm{ml}$. Tambahkan etanol $96 \%$ sampai tanda batas $25 \mathrm{ml}$, lalu campur. Letakkan dalam tangas es hingga terjadi pemisahan selama lebih kurang beberapa menit, saring melalui kertas saring.

\section{Pembuatan Larutan Baku}

Timbang seksama lebih kurang 0,02 gram hidrokuinon BP. Dimasukkan kedalam labu ukur $25 \mathrm{ml}$. Ditambahkan dengan $5 \mathrm{ml}$ etanol $96 \%$, lalu kocok sampai larut. Kemudian encerkan dengan etanol $96 \%$ sampai tanda. Campur $1 \mathrm{ml}$ larutan baku dengan $1 \mathrm{ml}$ larutan uji, kemudian dikocok hingga homogen.

\section{Identifikasi Sabun Pemutih Pembersih Wajah dengan Metode KLT}

Siapkan chamber yang telah dijenuhkan dengan fase gerak toluene : asam asetat glasial (8:2). Kemudian sampel ditotolkan pada plat KLT menggunakan pipa kapiler pada jarak $1,5 \mathrm{~cm}$ dari bagian bawah plat, jarak antara noda adalah $1,5 \mathrm{~cm}$ dibiarkan beberapa saat hingga mengering. Plat KLT yang telah mengandung cuplikan dimasukkan ke dalam chamber yang terlebih dahulu dijenuhkan. Dibiarkan hingga lempeng terelusi sempurna, kemudian plat KLT diangkat dan dikeringkan. Untuk mengetahui lokasi dari noda dapat dilihat dengan menggunakan cahaya ultra violet pada panjang gelombang $254 \mathrm{~nm}$. Kemudian diukur harga Rfnya.

\section{Prosedur Kerja Spektrofotometri UV-Vis \\ Pembuatan Larutan Baku Hidrokuinon 1000 ppm \\ Timbang $100 \mathrm{mg}$ Hidrokuinon. Larutkan dengan etanol $96 \%$ dengan labu takar $100 \mathrm{ml}$ ad sampai tanda}


homogenkan. Diperoleh konsentrasi larutan 1000 $\mathrm{mg} / \mathrm{L}$.

\section{Penentuan Panjang Gelombang Maksimum Hidrokuinon}

Dipipet $10 \mathrm{~mL}$ larutan baku hidrokuinon 1000 $\mathrm{mg} / \mathrm{L}$. Dilarutkan dengan etanol $96 \%$ dalam labu takar $100 \mathrm{ml}$ ad sampai tanda. Dihomogenkan hingga didapatkan konsentrasi 100 ppm. Diukur absorbansinya dengan Spektrofotometri Uv-Vis dengan panjang gelombang $200-400 \mathrm{~nm}$.

\section{Pembuatan Larutan Uji}

Ditimbang sampel masing - masing sebanyak 1,2 $\mathrm{g}$ dimasukkan ke dalam erlenmeyer $250 \mathrm{ml}$ dan diberi label pada masing - masing wadah. Ditamahkan 6 tetes $\mathrm{HCl} 4 \mathrm{~N}$ dan $10 \mathrm{ml}$ etanol. kemudian dipanaskan diatas penangas air sambil diaduk. Saring menggunakan kertas saring yang telah berisi $1 \mathrm{~g}$ Natrium Sulfat dan dimasukkan ke dalam labu ukur $10 \mathrm{ml}$. Tambahkan etanol $96 \%$ sampai batas tanda dan dikocok hingga homogen.

Identifikasi Sampel Secara Kualitatif

Masukkan larutan uji kedalam kuvet pada Spektrofotometri Uv - Vis. Amati spektrum yang terbentuk pada tiap sampel.

\section{Analisis Data}

Untuk menghitung Harga Rf dihitung sebagai jarak yang ditempuh oleh komponen dibagi dengan jarak tempuh oleh eluen (fase gerak) untuk setiap senyawa berlaku rumus sebagai berikut.

Perhitungan nilai Rf didasarkan atas rumus :

$$
R f=\frac{\text { Jarak titik pusat bercak dari titik awal }}{\text { Jarak bercak }}
$$

HASIL DAN PEMBAHASAN

\section{Hasil}

Dalam penelitian ini dilakukan dengan analisis kualitatif secara kromatografi lapis tipis dan spektrofotometri UV-Vis. Salah satu nya dengan melakukan pemeriksaan penandaan pada kemasan kosmetika.

\section{PEMBAHASAN}

Sampel yang di ambil dalam penelitian ini adalah sabun pemutih pembersih wajah berbentuk cair yang ada di tiga klinik kecantikan di Bandar Lampung. Pengambilan sampel ini dilakukan secara purposive sampling. Metode ini digunakan berdasarkan kriteria yang ditentukan oleh peneliti untuk dianggap mewakili karakteristik populasinya. Penulis tertarik mengambil sampel sabun pemuth pembersih wajah dalam bentuk cair dikarenakan penelitian sebelumnya telah melakukan penelitian tersebut namun dengan sampel yang berbentuk 
Volume 6, No. 1 April 2021, Hal 95 - 101

\begin{tabular}{llccc}
\hline 1 & Nama Kosmetik & $\checkmark$ & $\checkmark$ & $\checkmark$ \\
2 & Kegunaan & $\checkmark$ & $\checkmark$ & $\checkmark$ \\
3 & Cara Penggunaan & $\checkmark$ & $\checkmark$ & $\checkmark$ \\
4 & Komposisi & $\checkmark$ & $\checkmark$ & $\checkmark$ \\
5 & Nama dan Negara Produsen & $\checkmark$ & $\checkmark$ & $\checkmark$ \\
& Nama dan Alamat Lengkap & & & \\
6 & Pemohon Notifikasi & $\checkmark$ & $\checkmark$ & $\checkmark$ \\
& Nomor Batch & & & \\
7 & Ukuran, isi, berat bersih & $\checkmark$ & $\checkmark$ & $\checkmark$ \\
8 & Tanggal Kadaluarsa & $\checkmark$ & $\checkmark$ & $\checkmark$ \\
9 & Nomor Notifikasi & $\checkmark$ & $\checkmark$ & $\checkmark$ \\
10 & & & $\checkmark$ & $\checkmark$ \\
& & \multicolumn{2}{c}{ MS } & \multicolumn{2}{c}{ MS }
\end{tabular}

\section{Keterangan}

$=$ Ada

- = Tidak ada
MS = Memenuhi Syarat

TMS = Tidak memenuhi

Tabel 2. Hasil identifikasi warna bercak, perhitungan harga Rf dan selisih Rf Kromatografi Lapis Tipis

\begin{tabular}{|c|c|c|c|c|c|c|c|c|}
\hline \multirow[t]{2}{*}{ Sampel } & \multirow[t]{2}{*}{ Keterangan } & \multirow{2}{*}{$\begin{array}{l}\text { Warna } \\
\text { Bercak }\end{array}$} & \multicolumn{2}{|c|}{ Harga Rf } & \multicolumn{2}{|c|}{ Selisih Rf } & \multirow{2}{*}{$\begin{array}{l}\text { Rata-rata } \\
\text { Selisih } \mathrm{Rf}\end{array}$} & \multirow[t]{2}{*}{ Hasil } \\
\hline & & & 1 & 2 & 1 & 2 & & \\
\hline A & $\begin{array}{c}\text { Sampel } \\
\text { Baku } \\
\text { Sampel+Baku }\end{array}$ & $\begin{array}{l}\text { Putih } \\
\text { Ungu } \\
\text { Ungu }\end{array}$ & $\begin{array}{l}0,27 \\
0,09 \\
0,08\end{array}$ & $\begin{array}{l}0,24 \\
0,05 \\
0,22\end{array}$ & 0,18 & 0,19 & 0,185 & Negatif \\
\hline B & $\begin{array}{c}\text { Sampel } \\
\text { Baku } \\
\text { Sampel+Baku }\end{array}$ & $\begin{array}{l}\text { Putih } \\
\text { Ungu } \\
\text { Ungu }\end{array}$ & $\begin{array}{l}0,26 \\
0,09 \\
0,08\end{array}$ & $\begin{array}{l}0,25 \\
0,05 \\
0,21\end{array}$ & 0,17 & 0,20 & 0,185 & Negatif \\
\hline C & $\begin{array}{c}\text { Sampel } \\
\text { Baku } \\
\text { Sampel+Baku }\end{array}$ & $\begin{array}{l}\text { Putih } \\
\text { Ungu } \\
\text { Ungu }\end{array}$ & $\begin{array}{c}0 \\
0,09 \\
0,07\end{array}$ & $\begin{array}{c}0 \\
0,05 \\
0,20\end{array}$ & 0 & 0 & 0 & Negatif \\
\hline
\end{tabular}

Keterangan : Nilai Positif $(+)=$ Selisih $\mathrm{Rf} \leq 0,05$

Nilai Negatif $(-)=$ Selisif $\operatorname{Rf}>0,05$

Tabel 3. Hasil Identifikasi dengan Menggunakan Spektrofotometri UV-VIS 
JURNAL ANALIS FARMASI

Volume 6, No. 1 April 2021, Hal 95 - 101

\begin{tabular}{cccc}
\hline Sampel Merk & $\begin{array}{c}\text { Panjang } \\
\text { Gelombang } \\
\text { Maksimum }\end{array}$ & $\begin{array}{c}\text { Hasil } \\
\text { Absorbansi } \\
\text { Maksimum }\end{array}$ & Keterangan \\
\hline $\begin{array}{c}\text { Baku } \\
\text { Hidrokuinon }\end{array}$ & $294 \mathrm{~nm}$ & 0,696 & Positif \\
A & $257 \mathrm{~nm}$ & 1,027 & Negatif \\
B & $254 \mathrm{~nm}$ & 3,129 & Negatif \\
C & $273 \mathrm{~nm}$ & 0,599 & Negatif \\
\hline
\end{tabular}

\section{Gambar 1. Panjang Gelombang Maksimum Larutan Baku Hidrokuinopadat.}

Pada penelitian ini telah dilakukan identifikasi zat hidrokuinon dengan menggunakan metode Kromatografi Lapis Tipis (KLT). KLT merupakan suatu metode yang dapat memisahkan suatu senyawa campuran menjadi senyawa murni. Metode ini merupakan metode yang paling sering digunakan untuk pemisahan senyawa-senyawa campuran. Deteksi yang digunakan untuk pemisahan hidrokuinon yaitu menggunakan radiasi sinar ultraviolet $254 \mathrm{~nm}$ dikarenakan silika gel yang di pakai GF254 yang akan berflouresensi pada panjang gelombang tersebut. Penanganan sampel dilakukan dengan cara menimbang tiap sampel sebanyak 1,5 gram, kemudian sampel ditambahkan etanol $96 \%$ yang bertujuan untuk melarutkan hidrokuinon dalam sabun pemutih pembersih wajah. Setelah itu sampel dihomogenkan di tangas air bertujuan agar membantu mempercepat pemisahan dasar sabun. Setelah itu diletakan dalam tangas es untuk memisahkan hidrokuinon dari bahan dasar sabun. Selanjutnya disaring menggunakan kertas saring, penyaringan bertujuan untuk menyaring kemungkinan adanya partikel-partikel kecil yang ikut terbawa sehingga dapat mempengaruhi proses pemisahan, larutan yang di dapat dari penyaringan ini digunakan sebagai larutan uji atau larutan sampel. Selanjutnya pembuatan larutan baku pembanding sejumlah 0,02 gram hidrokuinon dilarutkan dengan etanol $96 \%$ sampai $10 \mathrm{ml}$. Penanganan kontrol positif (sampel dan baku pembanding) dengan cara dipipet 1 $\mathrm{ml}$ larutan baku dengan $1 \mathrm{ml}$ larutan uji dicampurkan kemudiaan dikocok hingga homogen [7]. Pada pemisahan ini plat yang digunakan sebagai fase diam adalah silika gel GF254 karena analit tidak berwarna sehingga digunakan silika gel GF254. Silika gel ini mampu berflouresensi dengan baik pada sinar UV dengan panjang gelombang $254 \mathrm{~nm}$. Ketiga larutan tersebut yang merupakan larutan sampel, kontrol positif dan baku pembanding ditotolkan pada plat dengan jarak dari dasar plat $1,5 \mathrm{~cm}$. Jarak penotolan sampel, kontrol positif dan baku pembanding yaitu 1,5 $\mathrm{cm}$. Jarak penotolan $1,5 \mathrm{~cm}$ dari dasar plat agar totolan tidak terendam oleh fase gerak. Sedangkan jarak penotolan larutan yang satu dengan yang lainnya agar tidak terjadi penumpukan bercak pada saat pengembangan. Penotolan dilakukan dengan menggunakan syringe berukuran $100 \mu \mathrm{l}$ penotolan dilakukan dengan cara menotolkan sedikit demi sedikit larutan yang telah dibuat. Kemudian setelah didapatkan bercak hidrokuinon dihitung harga Rf, sampel dapat dinyatakan positif jika hasil perhitungan harga Rf tidak lebih dari 0,05 [7].

Dari hasil penelitian dua kali pengulangan didapatkan harga Rf yang berbeda-beda dan hasil nya tidak terlalu jauh dari hasil pengulangan yang sebelumnya pada ketiga sampel. Hal ini disebabkan karena ada beberapa faktor yang mempengaruhi harga Rf antara lain : jumlah penotolan, suhu, uap dalam bejana pengembangan yang digunakan. Menurut peraturan Kepala Badan Pengawas Obat dan Makanan Republik Indonesia Nomor HK.03.1.23.08.11.07331 Tahun 2011 tentang metode analisis identifikasi dan penetapan kadar hidrokuinon dalam kosmetik secara Kromatografi Lapis Tipis dan Kromatografi Cair Kinerja Tinggi terdapat dua macam fase gerak untuk identifikasi hidrokuinon secara KLT yaitu: n-heksan : aseton (3:2) dan toluene : asam asetat glasial (8:2). Penelitiaan kali ini menggunakan fase gerak toluen : asam asetat glasial (8:2). Fase gerak yang dipakai berfungsi untuk mengikat/menarik senyawa yang diduga hidrokuinon sampai batas elusi dan menimbulkan bercak. Terdapat dua fase dalam kromatografi lapis tipis yaitu fase normal (normal phase) dan fase terbalik (reverse phase), normal phase adalah fase diamnya polar fase geraknya non 
polar sedangkan reverse phase adalah fase diamnya non polar, pada penelitian ini digunakan normal phase [1].

Pada penelitian sebelumnya dengan judul identifikasi hidrokuinon dalam sabun pembersih wajah yang beredar di toko online (Online Shop) secara Kromatografi Lapis Tipis (KLT) menunjukkan bahwa dari 12 sampel sabun $50 \%$ diantaranya teridentifikasi mengandung hidrokuinon dengan diperoleh harga Rf untuk masing-masing sampel yaitu sampel $E=0,05, F$ $=0,05, G=0,03, H=0,05, J=0,03, L=0,01$. Dengan demikian $50 \%$ sampel yang tidak teridentifikasi zat hidrokuinon dapat digunakan. Dari hasil penelitian sebelumnya maka penulis melakukan penelitian secara kualitatif dengan metode Kromatografi Lapis Tipis dan Spektrofotometri UV-Vis [1]. Berdasarkan hasil deteksi dengan menggunakan sinar UV254 nm dan Rf Kromatografi Lapis Tipis dari ketiga sampel sabun pemutih pembersih wajah yang terdiri dari sampel $A, B$, dan $C$ dapat disimpulkan bahwa sampel sabun pemutih pembersih wajah negatif mengandung hidrokuinon. Karena hasil tersebut menunjukkan bahwa dari ketiga sampel yang diperoleh selisih harga $\mathrm{Rf}$ dengan dua kali pengulangan hasil yang didapatkan untuk baku pembanding yaitu 0,07 dan untuk masingmasing sampel yaitu sebagai berikut : Sampel $A=$ 0,18 dan 0,19 , Sampel $B=0,17$ dan 0,20, Sampel $C=$ 0 . Pengujian dilakukan dengan dua kali pengulangan agar hasil yang didapatkan lebih akurat. Hal ini dapat dilihat dari hasil deteksi dibawah sinar UV254 nm yaitu terdapat atau timbul bercak berwarna ungu, pada penotolan sampel, baku pembanding dan kontrol positif memiliki warna yang sama dan jarak rambat yang tidak jauh berbeda. Bercak bewarna ungu, timbul dikarenakan adanya interaksi antara sinar UV dengan gugus kromofor yang terikat oleh ausokrom yang terdapat pada bercak tersebut. Dari hasil tersebut untuk lebih meyakinkan bahwa sabun pemutih pembersih wajah tersebut negatif mengandung hidrokuinon maka peneliti melanjutkan kepenelitiaan selanjutnya yaitu identifikasi hidrokuinon dengan menggunakan metode Spektrofotometri UV-Vis.

Spektrofotometer adalah alat yang digunakan dalam teknik spektrofotometri. Sesuai dengan namanya spektrofotometer terdiri dari spektrometer dan fotometer. Spektrometer adalah alat yang menghasilkan sinar dari spektrum dengan panjang gelombang tertentu dan fotometer merupakan alat pengukur intensitas cahaya yang diabsorpsi. Spektrofotometer merupakan alat yang digunakan untuk mengukur transmitan atau absorban dari suatu sampel sebagai fungsi dari panjang gelombang tertentu [5].

Adapun komponen-komponen didalam spektrofotometer salah satunya adalah kuvet. Kuvet spektroftometri merupakan alat yang digunakan sebagai wadah suatu sampel yang akan dianlisis nilai absorbansinya. Pada pengukuran didaerah sinar tampak digunakan kuvet kaca sedangkan pada daerah UV digunakan kuvet kuarsa. Kuvet yang digunakan harus bersih pada bagian beningnya (transparan) dan hanya boleh dipegang pada bagian buramnya, hal ini dilakukan karena kuvet dipakai untuk daerah sinar tampak dan kualitas data absorbans sangat tergantung pada cara pemakaian dan pemeliharaan sel. Sidik jari, lemak atau pengendapan zat pengotor pada dinding sel akan mengurangi transmisi, jadi selsel itu harus bersih sekali sebelum dipakai [8].

Pengujian dengan spektrofotometri UV-Vis dilakukan dengan cara kualitatif. Pengujian kualitatif dilakukan dengan mengidentifikasi sampel secara spektrofotometri. Uji kualitatif ini dilihat berdasarkan spektrum yang terbentuk yang ditunjukkan pada larutan baku hidrokuinon. Uji kualitatif ini yaitu uji yang dilakukan untuk menentukan ada tidaknya hidrokuinon dalam sabun pemuth pembersih wajah. Pengujian sampel sabun pemutih pembersih wajah secara kualitatif dilakukan dengan mengamati spektrum yang terbentuk tiap sampel [3].

Sebelum melakukan preparasi sampel hal yang harus terlebih dahulu dilakukan yaitu menyiapkan larutan baku hidrokuinon. Setelah itu dilakukan penentuan panjang gelombang maksimum. Setelah itu dilakukan preparasi sampel dengan cara ditimbang 1,2 gram sampel kemudian masukkan ke dalam erlenmeyer $250 \mathrm{ml}$. Lalu sampel ditambahkan 6 tetes $\mathrm{HCl} 4 \mathrm{~N}$ dengan tujuan agar hidrokuinon dapat terpisah dari senyawa lain yang ada di dalam sabun. Kemudian tambahkan $10 \mathrm{ml}$ etanol yang bertujuan untuk melarutkan hidrokuinon yang kemudian sampel tersebut dipanaskan. Tujuan pemanasan ini untuk menghomogenkan sampel. Setelah itu saring menggunakan kertas saring yang telah berisi 1 gram natrium sulfat yang bertujuan untuk menarik agar tidak adanya fase air lagi. Lalu hasil penyaringan dimasukkan ke dalam labu ukur $10 \mathrm{ml}$ setelah itu ditambahkan dengan etanol $96 \%$ sampai garis tanda dan dikocok hingga homogen [7].

Setelah larutan uji siap pengerjaan dilanjutkan dengan mencari panjang gelombang maksimum.

Panjang gelombang maksimum berada pada panjang gelombang $294 \mathrm{~nm}$. Tujuan dari pengukuran panjang gelombang yaitu untuk mengetahui serapan optimum 
dari larutan baku hidrokuinon. Selanjutnya panjang gelombang ini akan digunakan untuk mengukur absorbansi sampel. Setelah mengetahui hasil serapan optimum dari larutan baku hidrokuinon maka dilanjutkan dengan identifikasi sampel secara kualitatif [7].

Berdasarkan hasil pengujian tersebut diketahui bahwa hasil identifikasi secara spektrofotometri, Spektrum yang dibentuk oleh ketiga sampel menunjukan bahwa sampel A, B dan $C$ negatif mengandung hidrokuinon dikarenakan sampel tidak menunjukkan kesesuaian spektrum larutan baku dengan sampel pada panjang gelombang $294 \mathrm{~nm}$. Pada sampel A dan B dalam Lampiran 12 dan 13 tersebut menunjukkan adanya peak pada spektrum yang ditunjukkan pada larutan baku hidrokuinon dengan kadar absorbansi yang tinggi dari sampel $C$. Hal ini mungkin saja dikarenakan faktor pengenceran sehingga pada sampel $A$ dan $B$ nilai absorbansinya tinggi. Faktor pengenceran adalah faktor yang dilakukan agar bahan atau sampel tidak terlalu pekat sehingga memudahkan dalam pembacaan pada spektrofotometer. Setelah diketahui bahwa ketiga sampel tersebut negatif mengandung hidrokuinon maka tidak diperlukan pengujian secara kuantitatif.

\section{Kesimpulan dan Saran \\ Kesimpulan}

Hasil penelitian identifikasi secara kromatografi lapis tipis dan spektrofotometri UV-Vis dalam sabun pemutih pembersih wajah pada tiga klinik kecantikan di Bandar Lampung dapat disimpulkan bahwa Ho ditolak dan $\mathrm{Ha}$ diterima. Diperoleh hasil pengujian negatif pada sampel A, B, dan C secara kromatografi lapis tipis karena selisih Rf pada sampel $>0,05$. Diperoleh hasil pengujian negatif pada sampel $A, B$, dan $C$ secara spektrofotometri UV-Vis karena spektrum yang dihasilkan pada sampel tidak menyerupai spekrum larutan baku. Ketiga sampel tersebut memenuhi syarat sesuai dengan PERKA BPOM Republik Indonesia Nomor 18 Tahun 2015 Tentang Persyaratan Teknis Bahan Kosmetika.

\section{Saran}

Masyarakat harus lebih cermat dan teliti dalam memilih kosmetika, dalam memilih kosmetika, masyarakat dianjurkan memilih kosmetika yang memiliki nomor notifikasi dan juga nomor notifikasi tersebut terdaftar di situs resmi BPOM.Apabila masyarakat melakukan perawatan dan membeli kosmetika pada klinik ke cantikan sebaiknya selalu konsultasikan dengan dokter.

Bagi peneliti selanjutnya agar dapat melakukan identifikasi dan penetapan kadar pada senyawa-senyawa yang dilarang dalam kosmetika seperti asam retinoat pada sabun pemutih pembersih wajah
Anggraini, P., Primadiamanti, A., Ulfa, A.M. 2016. Identifikasi Hidrokuinon dalam Sabun Pembersih Wajah yang Beredar Melalui Toko Online (Online Shop) Secara Kromatografi Lapis Tipis. Jurnal analisis Farmasi. Akafarma Putra Indonesia Lampung. Lampung.Badan Pengawas Obat Dan Makanan Republik Indonesia. 2015.

Peraturan Kepala Badan Pengawas Obat Dan Makanan Republik Indonesia Nomor 18 Tentang Persyaratan Teknis Bahan Kosmetika. Jakarta.Irnawati., Sahumena, M.H., Dewi, W.A.N. 2016.

Analisis Hidrokuinon pada Krim Pemutih Wajah dengan Metode Spektrofotometri UV-Vis. Jurnal IImiah Farmasi Vol 5 No.3. Hal 229-237

Kinanti. S. 2013. Positioning Produk Kosmetik Wanita. Skripsi. Fakultas IImu Sosial dan Politik. Universitas Atma Jaya.

Yogyakarta.Kristianingrum, S. 2000 . Handout Spektroskopi Ultra Violet dan Sinar Tampak. https://www.academia.edu/28187225/handout spektroskopi ultra violet dan sinar tampak spektroskopi UV Vis.

Diakses pada 31 Mei 2018 pukul 09.00Peraturan Menteri Kesehatan Republik Indonesia Nomor

117/Menkes/PER/VII/2010. 2010. Tentang Notifikasi Kosmetika. Depkes RI. Jakarta.

Puspita, L., Feladita, N., Saputri, G.A.R. 2015. Identifikasi dan Penetapan Kadar Hidrokuinon dalam Krim Malam pada Empat Klinik Kecantikan Di Bandar Lampung Menggunakan Metode Kromatografi Lapis Tipis dan Spektrofotometri UV-Vis. Jurnal analisis Farmasi. Akafarma Putra Indonesia Lampung. Lampung.

Triyati E., 1985. Spektrofotometer Ultra-violet dan Sinar Tampak serta Aplikasinya dalam Oseanologi. Vol $X$ No.1. Hal 3947

\section{DAFTAR PUSTAKA}

